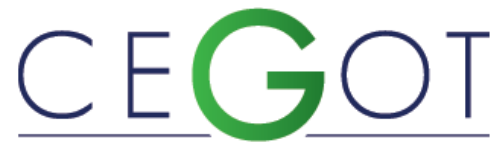

Centro de Estudos de Geografia e Ordenamento do Território
Geografia e Ordenamento do Território, Revista Eletrónica Centro de Estudos de Geografia e Ordenamento do Território http://cegot.org ISSN: 2182-1267

\title{
Protocolo de Avaliação Rápida de Rios Urbanos (PARU) como ferramenta de
}

\section{monitoramento ambiental.}

Rapid Urban River Assessment Protocol (RUAP) as an environmental tool.

Referência: Campos, Janaina Cassia; Nucci, João Carlos (2021). Protocolo de Avaliação Rápida de Rios Urbanos (PARU) como ferramenta de monitoramento ambiental. Revista de Geografia e Ordenamento do Território (GOT), n.o 21 (Junho). Centro de Estudos de Geografia e Ordenamento do Território, p. 121-138, dx.doi.org/ 10.17127/got/2021.21.005

\section{RESUMO}

O desenvolvimento de protocolos para um eficiente monitoramento da qualidade dos rios é de suma importância para o planejamento. O artigo apresenta o Protocolo de Avaliação Rápida de Rios Urbanos (PARU) e os resultados de sua aplicação no rio Palmital, localizado em área de manancial de abastecimento público da Região Metropolitana de Curitiba (RMC), no Estado do Paraná - Brasil. Foram analisados quatro pontos no terço inferior do rio e os resultados apontaram para um estado de baixa qualidade e de degradação ambiental. O PARU mostrou-se uma ferramenta simples e acessível de monitoramento dos ambientes fluviais e que pode ser utilizado por órgãos ambientais, assim como na educação formal e informal da população, favorecendo a participação popular nas tomadas de decisão que envolvem o planejamento urbano.

Palavras-chave: saúde dos rios, monitoramento dos rios, ambiente urbano, Curitiba, rio Palmital.

\section{ABSTRACT}

The development of protocols for an efficient monitoring of rivers quality is extremely important for urban planning. This paper shows up the Rapid Urban River Assessment Protocol (RUAP) and the results of its application in the Palmital River, located in an area of public water supply in the Metropolitan Region of Curitiba (RMC), in the State of Paraná Brazil. Four points were analyzed in the lower third of the river and it was figured out with low quality status of the river and with environmental degradation. RUAP was proved to be 
a simple and accessible tool for monitoring river environments and that can be used by environmental agencies, as well as in formal and informal education of the population, supporting the popular participation in decision-making involving urban plannings.

Keywords: river health, river monitoring, urban environment, Curitiba, Palmital River.

\section{Introdução}

O ser humano adquiriu, ao longo de sua história, uma grande capacidade de alterar a natureza, melhorando ou piorando sua qualidade, ou seja, aproveitando bem as funções que a natureza pode executar ou degradando-a e, assim, deixando de aproveitar suas funções.

Um dos elementos que compõem o ambiente natural e que podem passar por essa degradação, são os rios. Os rios podem refletir os processos que ocorrem na área de sua influência de escoamento, sejam eles antrópicos ou naturais (SARAIVA, 1999), porém são os processos derivados das ações antrópicas os que mais ameaçam a integridade desses ambientes, impactando o habitat, a qualidade da água e a biota aquática (KARR, 1999, ALLAN, 2004).

Dentre os processos que mais alteram o ambiente está o de urbanização, que ocorrendo de forma desordenada, devido à ausência ou ineficiência de planejamento, provoca impactos ambientais negativos muitas vezes irreversíveis.

Tucci (1999) faz uma relação dos principais impactos negativos da urbanização nos sistemas fluviais, dentre os quais se destacam: (i) o aumento da vazão máxima dos rios devido à impermeabilização das superfícies e ao aumento da capacidade de escoamento através de dutos e canais pluviais, bem como à intensificação das precipitações críticas de baixa duração, dada pelo aumento da temperatura do ambiente e produção de ilhas de calor; (ii) o aumento da produção de sedimentos e material sólido ocasionado pela desproteção das superfícies dada pela supressão da vegetação, que provocam o assoreamento e redução da capacidade de escoamento dos rios; (iii) deterioração da qualidade da água, pelo aporte de poluição difusa e pontual ao rio. Adicionalmente a estes, existem os impactos causados pela forma desorganizada de implantação da estrutura urbana, como projetos e obras de drenagem inadequados ou a utilização em larga escala da canalização dos rios, sem o devido estudo dos efeitos à jusante. 
A compreensão desses processos em toda sua complexidade requer uma visão integradora, para além da qualidade da água, conforme enfatiza Rodrigues (2009):

\begin{abstract}
Os ecossistemas aquáticos são integrados por componentes e processos bem mais amplos do que uma análise focada apenas no componente água permite contemplar. A compreensão de todos esses componentes e processos, bem como da qualidade global do sistema só é possível a partir de uma análise que integre todos os fatores inter-atuantes envolvidos. Esta análise deve englobar, além das características intrínsecas à determinação da qualidade da água, também aquelas que determinam a qualidade do meio, bem como a relação entre estas características (RODRIGUES, 2009, p. 8).
\end{abstract}

Dentre as formas de análise integrada dos sistemas aquáticos encontra-se o Protocolo de Avaliação Rápida de Rios (PAR), uma ferramenta simplificada de avaliação da estrutura e funcionamento dos ambientes fluviais, que permite estabelecer uma pontuação para o estado em que o rio se encontra (CALLISTO et al., 2002; RODRIGUES, 2008; RADTKE, 2015).

O PAR tem sua origem no Protocolo de Avaliação Visual de Habitat -Visual-based Habitat Assessment - que integra os Protocolos de Bioavaliação Rápida - Rapid Bioassessment Protocols (RBPs), desenvolvidos para atender a necessidade de reestruturação dos programas de monitoramento norte-americanos, de forma a suprir as demandas que despontaram na década de 1980. Esses protocolos são ferramentas de monitoramento de baixo custo, cientificamente válidos e que geram resultados rápidos para as decisões de gestão (BARBOUR et al., 1999).

Apesar da ampla utilização por órgãos ambientais dos protocolos de avaliação física dos habitats para monitoramento de recursos hídricos nos EUA e em outras regiões do mundo, o uso destes protocolos é pouco difundido no Brasil (BERSOT, MENEZES, ANDRADE, 2015), sendo considerados, principalmente, no âmbito acadêmico.

No Brasil, os protocolos de avaliação rápida das condições físicas do ambiente recebem várias denominações, tais como: Protocolo de Avaliação Rápida da Diversidade de Habitats (DILLENBURG, 2007, KRUPEK, 2010, FRANÇA et al., 2010), Protocolos para Avaliação Rápida de Integridade Ambiental de Rios e Riachos (MINATTI-FERREIRA; BEAMOUND, 2004, MINATTI-FERREIRA; BEAMOUND, 2006), Protocolo de Caracterização de Condições Ecológicas (CALLISTO; MORENO, 2006) e Protocolo de Avaliação Ecológica Rápida (PIMENTA; PENA; GOMES, 2009). 
No caso dos sistemas fluviais, a maioria dos estudos brasileiros utiliza, na íntegra ou adaptados, o protocolo de Callisto et al. (2002) ou o de Rodrigues e Castro (2008). No primeiro, os autores modificaram os protocolos da Agência de Proteção Ambiental de Ohio (EUA) (EPA,1987) e de Hannaford et al. (1997), fazendo adaptações para as condições dos ecossistemas fluviais nos estados de Minas Gerais e Rio de Janeiro; o protocolo modificado foi aplicado em trechos de rios no Parque Nacional da Serra do Cipó (MG) e no Parque Nacional da Bocaína (RJ), por estudantes de graduação em Ciências Biológicas e pósgraduação em Ecologia da Universidade Federal de Minas Gerais (UFMG), sendo utilizado como ferramenta de monitoramento e de ensino e pesquisa. O PAR de Rodrigues e Castro (2008) também foi proposto como ferramenta de monitoramento, mas com o enfoque de promover a participação social na gestão dos recursos hídricos. Após uma oficina de capacitação, voluntários aplicaram em trechos de rios de alto e baixo curso inseridos em campos rupestres, o protocolo que foi adaptado de Barbour et al (1999), tendo como situação referência as condições ambientais encontradas no interior do Parque Estadual do Itacolomi, Ouro Preto (MG).

Tomando estes dois protocolos como base, Campos e Nucci (2019) fizeram adaptações para aplicação do protocolo em rios urbanos. O procedimento consistiu na compatibilização e posterior seleção dos critérios, de forma a atender recortes espaciais para estudos realizados em rios localizados em áreas urbanas. Novos critérios foram criados e os parâmetros indicativos das condições do rio foram adaptados para uma linguagem mais acessível ao público geral, de forma a contribuir com a utilização do PAR pela comunidade, favorecendo a participação social.

O protocolo adaptado por Campos e Nucci (2019) foi aplicado, pelos próprios autores, no rio Palmital (Região Metropolitana de Curitiba -RMC). Os resultados demonstraram algumas inconsistências entre os critérios e parâmetros propostos e o observado em campo, fato que levou Campos (2020) a realizar uma análise detalhada das divergências e similaridades entre este PAR e o ambiente e posterior triangulação destas informações com a literatura especializada, resultando no então denominado Protocolo de Avaliação Rápida de Rios Urbanos (PARU). 
O PARU compreende critérios e parâmetros que buscam expressar as particularidades da paisagem fluvial urbana, pouco explorada em outros protocolos, principalmente naqueles baseados em ambientes minimamente degradados.

O objetivo deste trabalho é, portanto, apresentar o Protocolo de Avaliação Rápida de Rios Urbanos (PARU) e os resultados de sua aplicação em quatro pontos do rio Palmital (Curitiba, Paraná, Brasil), discutindo sua potencial utilização como uma ferramenta de monitoramento ambiental.

\section{Método}

O rio Palmital é afluente da margem direita do rio Iraí que, junto com o rio Atuba, entre outros da parte leste do município de Curitiba, formam o rio Iguaçu, o maior rio totalmente paranaense. Ao longo de seus $1.320 \mathrm{~km}$ de extensão, o rio Iguaçu passa pelos três planaltos paranaenses até desaguar no rio Paraná (SUDERHSA, 2002, SEMA-PR, 2010).

Essa área de planalto, conhecida como a do Alto Iguaçu, está próxima aos contrafortes da Serra do Mar, com nascentes de rios que alimentam represas, compondo importantes áreas de mananciais que fornecem água para a RMC.

O rio Palmital apresenta uma vazão de $372 \mathrm{l} / \mathrm{s}$ e sua bacia hidrográfica abrange uma extensão territorial de aproximadamente $93 \mathrm{~km}^{2}$, na qual estão inseridos parte do município de Colombo, em sua montante, e parte do município de Pinhais, na região de jusante (ANDREOLI, 1999, SUDERHSA, 2002), conforme pode ser observado na Figura 1.

A bacia de drenagem do rio Palmital apresenta diversos usos, predominando o uso urbano na parte inferior e rural na parte superior, embora com ocorrência de núcleos urbanos dispersos (SUDERHSA, 2002). As áreas urbanas da bacia são densamente povoadas e influenciam negativamente na qualidade da água do rio Palmital, apesar de sua bacia fazer parte da área de interesse de proteção dos mananciais de abastecimento da RMC, definida pelo Decreto Estadual № 4435/2016 (PARANÁ, 2016).

Do rio Palmital foram selecionados quatro pontos para a aplicação do protocolo (Figura 2), definidos com base em dois critérios: 1) acessibilidade aos pontos para observação e 2) 
diversidade de ambientes para melhor abranger todos os critérios e parâmetros do protocolo.

O protocolo utilizado foi o PARU (CAMPOS, 2020), cujos critérios e parâmetros estão descritos e apresentados no Quadro 1.

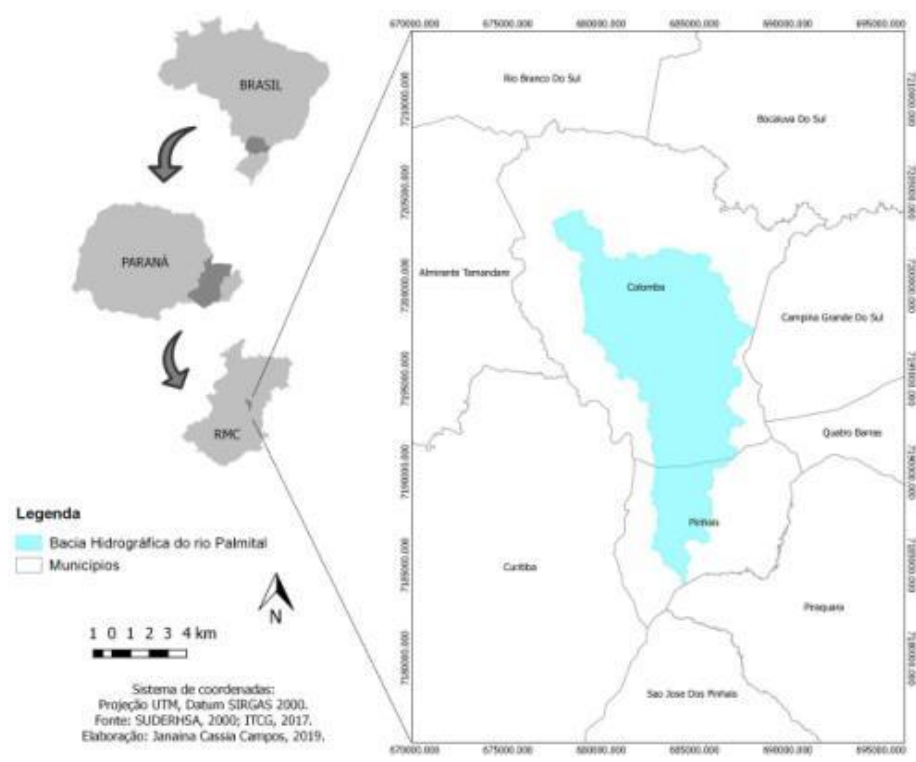

Figura 1 - Localização da bacia do rio Palmital.
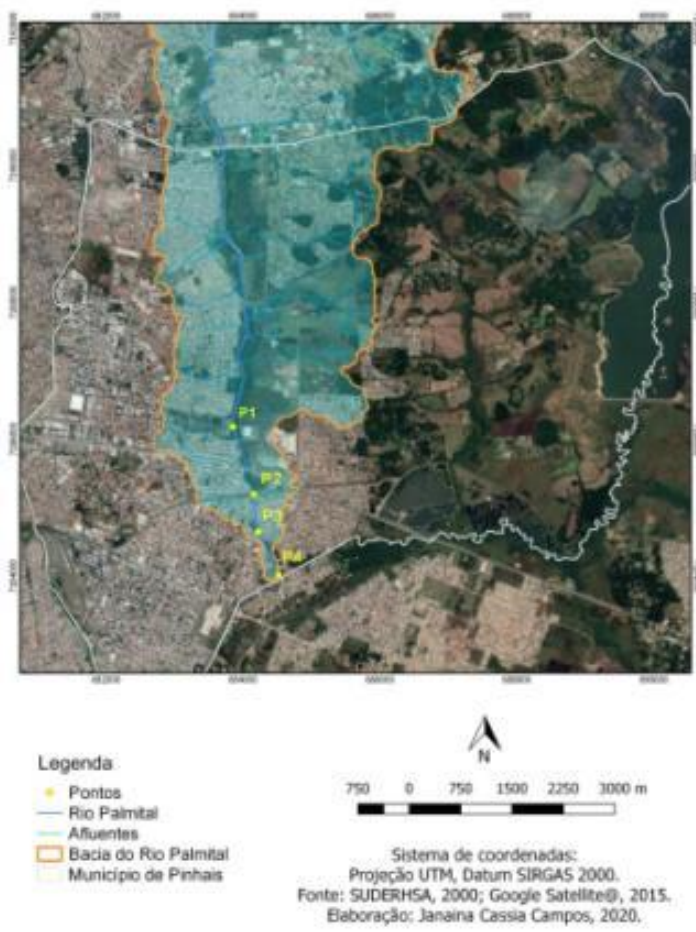

Figura2 - Localização dos pontos de observação 
Quadro 1 - Protocolo de avaliação rápida de rios urbanos (PARU)

\begin{tabular}{|c|c|c|c|c|}
\hline \multirow{2}{*}{ CRITÉRIO } & \multicolumn{4}{|c|}{ CONDIÇĀO DO RIO (PARĀMETROS) } \\
\hline & Ótima & Boa & Regular & Ruim \\
\hline $\begin{array}{l}\text { Estabilidade } \\
\text { das margens }\end{array}$ & Margem estável, sem evidência de erosão. & $\begin{array}{l}\text { Margem moderadamente estável, com pequena } \\
\text { evidência de erosasa somente nas curvas ou com } \\
\text { erosão em menos de } 1 / 4 \text { do trecho observado. }\end{array}$ & $\begin{array}{l}\text { Margem moderadamente estável, com deslizamentos } \\
\text { nas curvas ou erosão em menos da metade do trecho } \\
\text { observado. }\end{array}$ & $\begin{array}{l}\text { Margem instável, com evidência de erosão em mais da } \\
\text { metadede de sua extensáo. Margens canalizadas ou } \\
\text { retificadas sem vegetacăo restabelecida. }\end{array}$ \\
\hline $\mathrm{MD}$ & 10 & $8 \quad 7$ & 4 & 2 \\
\hline ME & 10 & 8 & $\frac{4}{4}$ & 0 \\
\hline $\begin{array}{l}\text { Presença e } \\
\text { estado de } \\
\text { conservaçăo } \\
\text { da mata ciliar }\end{array}$ & $\begin{array}{l}\text { A vegetação ocupa quase toda a margem e é composta } \\
\text { predominantemente por espécies arbustivas e arbóreas, } \\
\text { sem sinais de degradaçâo causados por atividades } \\
\text { humanas. }\end{array}$ & $\begin{array}{l}\text { A vegetaçãa ocupa mais de } 3 / 4 \text { da margem e as } \\
\text { espécies arbóreas e arbustivas sáo predominantes } \\
\text { em relą̧ắo às herbáceas. }\end{array}$ & $\begin{array}{l}\text { A vegetação ocupa mais da metade da margem e a } \\
\text { vegetaçăo herbácea é abundante. }\end{array}$ & $\begin{array}{l}\text { A vegetaçãa é praticamente inexistente. O solo está } \\
\text { exposto à intempéries naturais ou está } \\
\text { impermeabilizado ou ocupado por edificą̧óes. }\end{array}$ \\
\hline & 10 & $\begin{array}{lll}8 & 7 & 6 \\
\end{array}$ & 3 & $2 \quad 1$ \\
\hline $\mathrm{ME}$ & 10 & 8 & 5 & 2 \\
\hline $\begin{array}{l}\text { Ocupação } \\
\text { das margens } \\
\text { do rio }\end{array}$ & $\begin{array}{l}\text { A mata ciliar compreende toda (ou quase toda) a } \\
\text { margem do rio e é composta principalmente por } \\
\text { espécies arbóreas e arbustivas. }\end{array}$ & $\begin{array}{l}\text { Mais da metade da margem é composta por mata } \\
\text { ciliar, independentemente do tipo de vegetação. }\end{array}$ & $\begin{array}{l}\text { Mais da metade da margem tem solo exposto ou é } \\
\text { ocupada por estruturas urbanas, como residências, } \\
\text { comércios, indústrias, sistema viário, etc. }\end{array}$ & $\begin{array}{l}\text { A margem é ocupada prioritariamente por estruturas } \\
\text { urbanas, como residéncias, comércios, indústrias, } \\
\text { sistema viário, etc. }\end{array}$ \\
\hline MD & 10 & 8 & 3 & 0 \\
\hline $\mathrm{ME}$ & 10 & $\begin{array}{lll}8 & 7 & 6 \\
\end{array}$ & 3 & 0 \\
\hline \multirow[t]{2}{*}{$\begin{array}{l}\text { Resíduos } \\
\text { sólidos (lixo) }\end{array}$} & $\begin{array}{l}\text { Não se observam residuos sólidos no fundo nem nas } \\
\text { margens do rio. }\end{array}$ & $\begin{array}{l}\text { Existem resíduos sólidos em pouca quantidade nas } \\
\text { margens, que aparentemente ainda não } \\
\text { alcançaram o canal fluvial. Sãa em geral recentes e } \\
\text { estāo próximos às pontes e ruas. }\end{array}$ & $\begin{array}{l}\text { Existem residuos sólidos em pequena quantidade no } \\
\text { fundo do rio ou nas margens. Podem estar } \\
\text { concentrados em pequenas porçôes ou dispersos. }\end{array}$ & $\begin{array}{l}\text { Existe uma grande quantidade resíduos sólidos no } \\
\text { fundo e/ou nas margens do rio. }\end{array}$ \\
\hline & 10 & $\begin{array}{ll} & 8 \\
\end{array}$ & $5 \quad 4$ & 1 \\
\hline \multirow[t]{2}{*}{$\begin{array}{l}\text { Esgoto } \\
\text { doméstico e } \\
\text { efluente } \\
\text { industrial }\end{array}$} & $\begin{array}{l}\text { Não se observam canalizaçōes, nem odor ou presença } \\
\text { de espuma, mancha escura ou óleo na água ou } \\
\text { sedimento. }\end{array}$ & $\begin{array}{l}\text { Existem uma das seguintes evidências: 1) } \\
\text { canalizaçóes nas margens, } 2 \text { ) espumaa na água ou } \\
\text { sedimentof; 3) odor caracteristico de esgoto } \\
\text { doméstico ou outro odor forte na água. }\end{array}$ & $\begin{array}{l}\text { Existem duas das seguintes evidências: 1) } \\
\text { canalizacóes nas margens; 2) espuman na água ou } \\
\text { sedimento; 3) odor caracteristico de esgoto doméstico } \\
\text { ou odor forte não identificado; 4) mancha escura ou } \\
\text { óleo na água ou sedimento. }\end{array}$ & 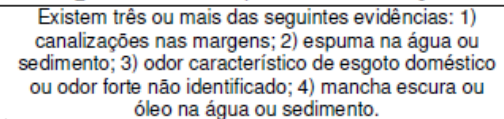 \\
\hline & 10 & $\begin{array}{lll}8 & 7 & 6 \\
\end{array}$ & 5 & 2 \\
\hline \multirow[t]{2}{*}{$\begin{array}{l}\text { Alteraçōes } \\
\text { antróicas no } \\
\text { canal fluvial }\end{array}$} & $\begin{array}{l}\text { Ausência de alteraçōes antrópicas no canal fluvial, } \\
\text { como dragagens, pontes, diques e estabilizaçāo } \\
\text { artificial das margens. }\end{array}$ & $\begin{array}{l}\text { Pouca modificaçãa presente, em geral em área de } \\
\text { apoio de pequenas pontes ou evidência de } \\
\text { canalizaçoes antigas, mas com ausência de } \\
\text { canalizaçōes recentes. }\end{array}$ & $\begin{array}{l}\text { Presença de pontes com grande estrutura de } \\
\text { sustentacáo, estruturas que dificultem o fluxo de água } \\
\text { no rio (diques, tubos, etc.) ou de escoramento nas } \\
\text { margens e evidências de dragagem. }\end{array}$ & $\begin{array}{l}\text { O rio encontra-se retificado e canalizado, com as } \\
\text { margens totalmente (ou quase totalmente) cimentadas. }\end{array}$ \\
\hline & $\begin{array}{rr}10 & 9 \\
\end{array}$ & $\begin{array}{ll}8 & 7 \\
\end{array}$ & $\begin{array}{lll}5 & 4 & 3 \\
\end{array}$ & $\begin{array}{ll}2 & 1 \\
\end{array}$ \\
\hline \multirow[t]{2}{*}{$\begin{array}{l}\text { Deposiçāo } \\
\text { de } \\
\text { sedimentos }\end{array}$} & $\begin{array}{c}\text { Ausência de bancos de areia (feiçōes deposicionais que } \\
\text { podem aparecer na forma de ilhas ou de barras que se } \\
\text { desenvolvem ao longo das margens). As águas correm } \\
\text { normalmente. }\end{array}$ & $\begin{array}{l}\text { Há pequenos bancos de areia recentes ou } \\
\text { pequenos alargamentos existentes que não afetam } \\
\text { as condiçōes de escoamento da água. }\end{array}$ & $\begin{array}{l}\text { Os bancos de areia são extensos e podem interferir no } \\
\text { escoamento da água no rio. A deposiçāo de novos } \\
\text { sedimentos mostra que os bancos estâo se } \\
\text { desenvolvendo. }\end{array}$ & $\begin{array}{l}\text { Há muito sedimento depositado no rio, indicando alto } \\
\text { nivel de assoreamento. Os bancos de areia se } \\
\text { estendem ao longo das margens e do rio e atrapalham } \\
\text { o escoamento da água. }\end{array}$ \\
\hline & $\begin{array}{ll}10 & 9 \\
\end{array}$ & $\begin{array}{ll}8 & 7 \\
\end{array}$ & 4 & $\begin{array}{ll}2 & 1 \\
\end{array}$ \\
\hline \multirow[t]{2}{*}{$\begin{array}{l}\text { Substratos } \\
\text { e/ou habitat } \\
\text { disponiveis }\end{array}$} & $\begin{array}{l}\text { Existem várís tipos e tamanhos de substratos e } \\
\text { habitats estáveis para a biota aquática, tais como } \\
\text { galhos e troncos, cascalhos, folhas e plantas aquáticas. }\end{array}$ & $\begin{array}{l}\text { Existem muitos galhos e troncos, cascallos, folhas } \\
\text { e plantas aquáticas, mas estáo totalmente } \\
\text { disponiveis. }\end{array}$ & $\begin{array}{l}\text { Existem poucos galhos e troncos, cascallhos, folhas e } \\
\text { plantas aquáticas, e não estāo totalmente disponiveis. }\end{array}$ & $\begin{array}{l}\text { Ausência de substratos e habitats estáveis disponiveis. } \\
\text { Nâo existem gallhos ou troncos, cascalhos, folhas e } \\
\text { plantas aquáticas, ou estâo soterrados. }\end{array}$ \\
\hline & 10 & $8 \quad$ aisponive 7 . & $\begin{array}{lll}5 & 4 & 3 \\
\end{array}$ & $\begin{array}{l}\text { plantas aquaticas, ou estao solert } \\
2\end{array}$ \\
\hline \multirow[t]{2}{*}{ Soterramento } & $\begin{array}{l}\text { Não se observa acúmulo de lama ou areia no fundo do } \\
\text { rio. }\end{array}$ & $\begin{array}{l}\text { Pouca quantidade de lama } e \text { areia cobrem of ofundo } \\
\text { do rio, sendo possiviel ver bastante substratos } \mathrm{e} \\
\text { habitats disponiveis. }\end{array}$ & $\begin{array}{l}\text { Boa parte do fundo do ro está coberto por lama ou } \\
\text { areia, mas ainda é possivel ver substratos e habitats } \\
\text { disponiveis. }\end{array}$ & $\begin{array}{l}\text { O fundo do rio apresenta muita lama ou areia, cobrindo } \\
\text { os substratos e habitats disponiveis. }\end{array}$ \\
\hline & 10 & 7 & 4 & 2 \\
\hline Animais & $\begin{array}{l}\text { Observam-se com facilidade peixes, insetos aquáticos, } \\
\text { anfibios (sapos, râs ou pererecas). }\end{array}$ & $\begin{array}{l}\text { Observam-se poucos peixes, insetos aquáticos, } \\
\text { anfibios (sapos, rás ou pererecas) ou mamíreros } \\
\text { silvestres (como a capivara) no rio ou nas margens. }\end{array}$ & Observam-se apenas aves no rio ou nas margens. & $\begin{array}{l}\text { Não é visivel nenhum animal aquático ou sivestre no } \\
\text { rio ou margens. }\end{array}$ \\
\hline & $\begin{array}{ll}10 & 9 \\
\end{array}$ & 8 - 8 & 5 & 1 \\
\hline
\end{tabular}

Legenda: $\mathrm{MD}=$ margem direita; $\mathrm{ME}=$ margem esquerda.

Fonte: Campos (2020) 
O quadro 1 foi utilizado para as anotações em trabalho de campo, que foi realizado no dia 18 de junho de 2020. Para cada critério foi atribuída uma pontuação referente ao estado em que o rio se encontra no ponto observado, sendo que o somatório das notas indica a condição geral do rio naquele ponto.

Os três primeiros critérios possuem relação com as margens do rio, cuja avaliação em campo ocorre separadamente, margem direita (MD) e margem esquerda (ME), sendo feita, posteriormente, a média destas notas.

Destaca-se, no quadro 1, a escala gradativa das notas, que flexibiliza a escolha da nota dentro de um mesmo parâmetro representativo da condição do rio, o que amplia as possibilidades de avaliação em campo e favorece a diferenciação das condições entre os pontos de observação.

A condição do ponto analisado é dada pela somatória da pontuação das notas, conforme Tabela 1.

Tabela 1 - Condição geral do rio conforme pontuação total do PARU

\begin{tabular}{|l|l|}
\hline PONTUAÇÃO & CONDIÇÃO GERAL DO RIO \\
\hline $81-100$ & Ótima (recuperado) \\
\hline $51-80$ & Boa (alterado) \\
\hline $21-50$ & Regular (impactado) \\
\hline $0-20$ & Ruim (muito impactado) \\
\hline
\end{tabular}

Fonte: Campos (2020)

A condição ótima indica um rio recuperado, enquanto a boa aponta um rio alterado, mas com alguma qualidade. Na condição regular o rio apresenta impactos negativos relevantes, com perda significativa de sua qualidade, que passa a ser muito maior na condição ruim, em virtude do elevado impacto negativo.

\section{Resultados e discussão}

Como as condições hidrometeorológicas interferem nas condições do rio e no próprio resultado do PARU, antes de apresentá-los é importante destacar que a primeira 
observação in locu na ocasião da aplicação do protocolo, no dia 18 de junho de 2020, foi que o nível do rio estava baixo. Na ausência dos dados de vazão, foram utilizados dados pluviométricos para representar as condições hidrometeorológicas, por proporcionarem informações, mesmo que indiretas, acerca da condição de fluxo e preenchimento do canal fluvial.

Dados da estação pluviométrica Curitiba, código 02549006 do INMET, localizada na Bacia do Alto Iguaçu, demonstram que a precipitação nos primeiros dezoito dias de junho de 2020 totalizaram 96,0 mm, valor acima da média para este mês nesta estação, segundo o estudo de pluviometria apresentado no Plano de Bacia do Alto Iguaçu e Afluentes do Alto Ribeira (SUDERHSA, 2007). No entanto, a precipitação na mesma estação pluviométrica foi em média $20 \%$ do total esperado para o trimestre antecedente, representando um volume consideravelmente inferior à média mensal nestes meses, conforme demonstrado na Figura 3, corroborando com a observação visual do baixo nível de água do rio Palmital no dia da aplicação do protocolo.

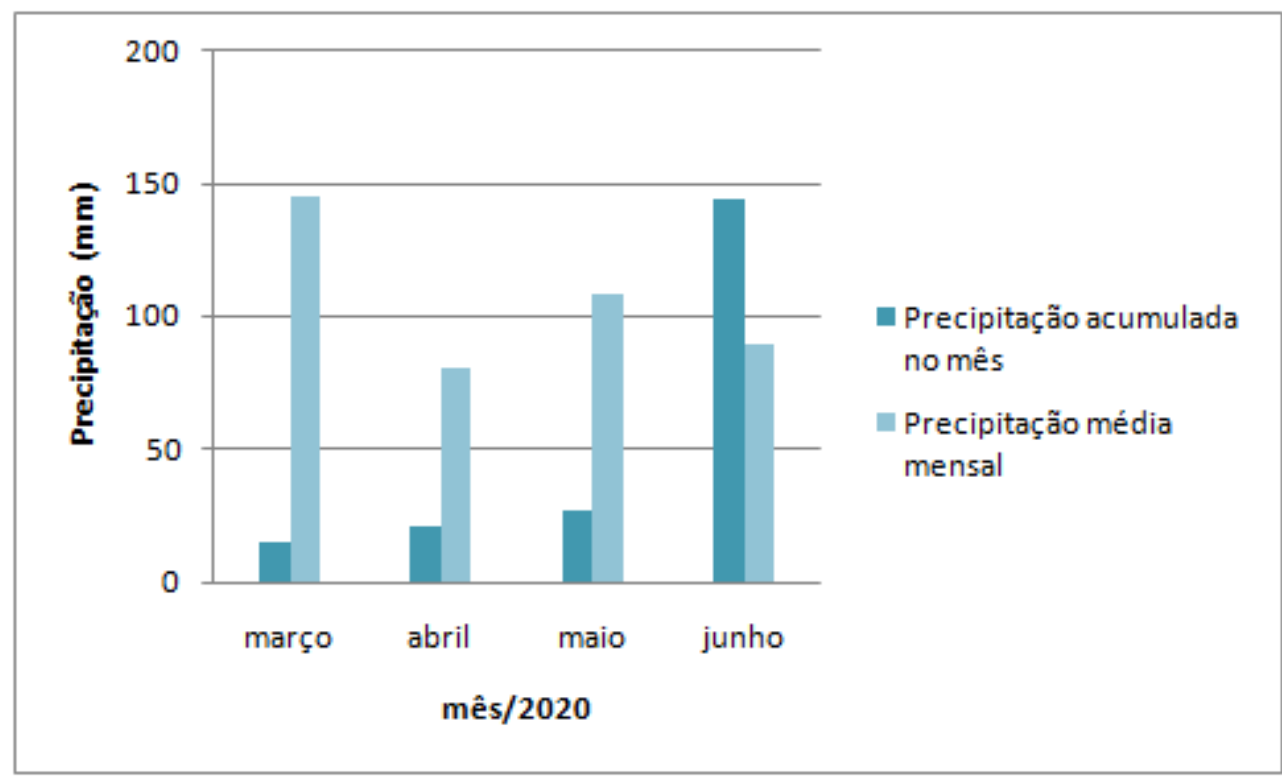

Figura 3 - Chuva acumulada mensal na Estação Curitiba (março a junho - 2020) Fonte: www.inmet.gov.br

Cabe, também, o destaque para a atual situação precária do abastecimento público de água para a região, que está passando por interrupções semanais no fornecimento de água que é controlado pela Companhia de Saneamento do Paraná (Sanepar). O rodízio, implantado em 
março de 2020, reduz diariamente o fornecimento de água para $20 \%$ da população e é uma das medidas adotadas para garantir o abastecimento público diante do preocupante nível de água dos quatro reservatórios de abastecimento da RMC, que registram em julho a média de 34\% (PARANÁ, 2020).

Os dados oriundos da aplicação do PARU apontaram que a condição geral do rio Palmital nos pontos observados varia de ruim a regular, sendo que a pior condição foi constatada no ponto 2 e a melhor no ponto 3, conforme Tabela 2 e Figura 4.

Tabela 2 - Dados gerais da aplicação do PARU no Rio Palmital

\begin{tabular}{|l|c|c|c|c|}
\hline \multirow{2}{*}{ Critérios } & \multicolumn{3}{|c|}{ Pontos de observação } \\
\cline { 2 - 5 } & $\mathbf{1}$ & $\mathbf{2}$ & $\mathbf{3}$ & $\mathbf{4}$ \\
\hline Estabilidade das margens & 5,0 & 3,0 & 7,0 & 3,0 \\
\hline Presença e estado de conservação da mata ciliar & 7,0 & 3,5 & 6,5 & 4,0 \\
\hline Ocupação das margens do rio & 6,5 & 4,0 & 6,5 & 5,0 \\
\hline Resíduos sólidos & 0 & 0 & 0 & 0 \\
\hline Esgoto doméstico e efluente industrial & 0 & 0 & 0 & 0 \\
\hline Alterações antrópicas no canal fluvial & 5,0 & 3,0 & 5,0 & 5,0 \\
\hline Deposição de sedimentos & 5,0 & 3,0 & 8,0 & 5,0 \\
\hline Substratos e/ou habitats disponíveis & 2,0 & 0 & 2,0 & 2,0 \\
\hline Soterramento & 2,0 & 0 & 2,0 & 2,0 \\
\hline Animais & 0 & 0 & 3,0 & 3,0 \\
\hline Total & $\mathbf{3 2 , 5}$ & $\mathbf{1 6 , 5}$ & $\mathbf{4 0 , 0}$ & $\mathbf{2 9 , 0}$ \\
\hline Condição geral & Regular & $\mathbf{R u i m}$ & $\mathbf{2}$ & Regular \\
\hline
\end{tabular}

Fonte: Elaborado pelos autores

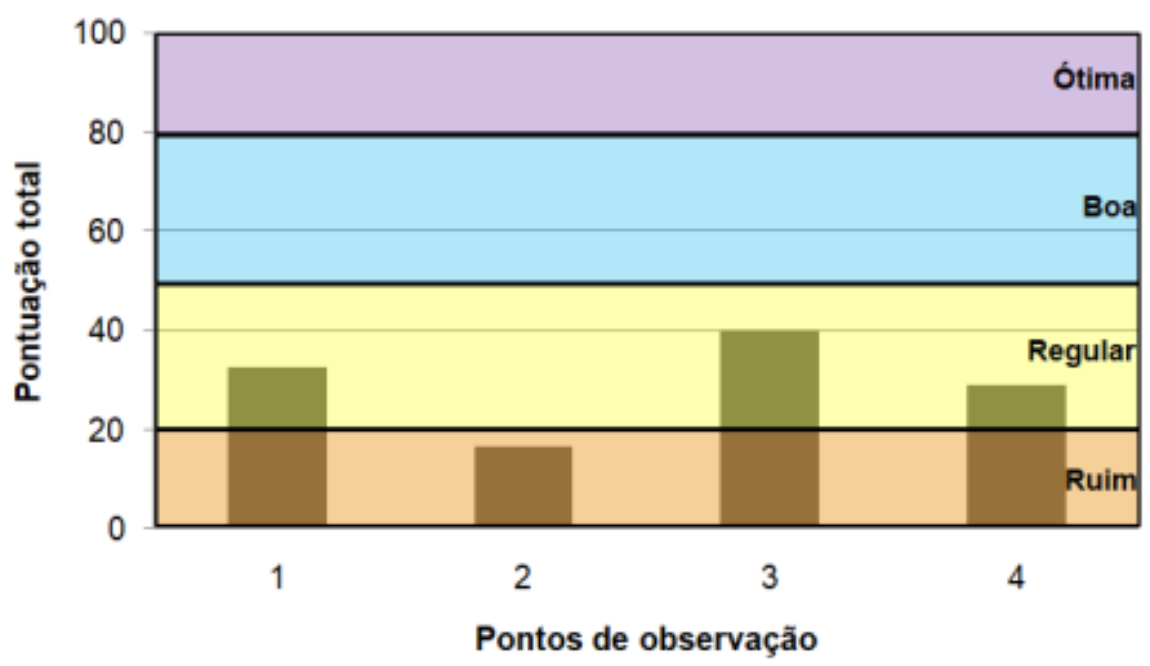

Figura 4 - Condição geral do rio Palmital

Fonte: Elaborado pelos autores 
O uso da terra no entorno dos pontos de observação é predominantemente residencial, apesar de serem avistados alguns comércios e indústrias. Além dos espaços edificados e espaços viários pavimentados, encontram-se fragmentos de mata ciliar nos quatro pontos, estando a cobertura vegetal em melhor estado de conservação nos pontos 1 e 3 . Também nestes pontos, as margens apresentaram maior estabilidade. A ocupação e estabilidade das margens bem como a presença e estado de conservação da mata ciliar nos pontos de observação estão representados pelas imagens da Figura 5.

Assim como a estabilidade das margens, a deposição de sedimentos, o soterramento e os substratos e/ou habitats disponíveis estão relacionados com a presença e estado de conservação da mata ciliar e com fenômenos que ocorrem à montante, relacionados ao uso e ocupação da terra na bacia de drenagem. Tais critérios são, portanto, indicadores de poluição difusa.

Sobre a deposição de sedimentos, foi evidenciada a presença de bancos de areia, formando ilhas e barras nas margens, em todos os pontos, sendo menos acentuada no ponto 3 e mais acentuada no ponto 2. Este é um dos critérios cuja avaliação é afetada pelo nível de água baixo no leito do rio, uma vez que os bancos de areia são mais visíveis nestas condições.

Em se tratando dos critérios soterramento e substratos e/ou habitats disponíveis, foi constatada a presença de grande quantidade de lama e areia no fundo do rio em todos os pontos observados e, consequentemente, a escassez de substratos e habitats disponíveis para a biota aquática. Na Figura 6 estão representados alguns exemplos de soterramento e deposição de sedimentos observados in locu.

A poluição pontual é representada no PARu pelos critérios resíduos sólidos e esgoto doméstico e/ou efluente industrial, apresentados na figura 7. Nos quatro pontos, foram observados muitos resíduos sólidos tanto nas margens quanto no leito do rio. Embora tenham sido detectados parâmetros representativos da existência de esgoto doméstico e/ou efluente industrial no ponto 1, não há registro visual nas imagens do ponto 1. Já a imagem do ponto 2 apresenta dois locais de escoamento de efluentes, do lado esquerdo a canalização é visível enquanto do lado direito é observada a presença de espumas na água. Nos pontos 3 e 4 são apresentadas imagens que demonstram a presença de mancha de óleo 
sobre a água. Um parâmetro indicador de esgoto doméstico, que não é representado nas imagens, mas foi detectado em todos os pontos, é o odor característico na água.

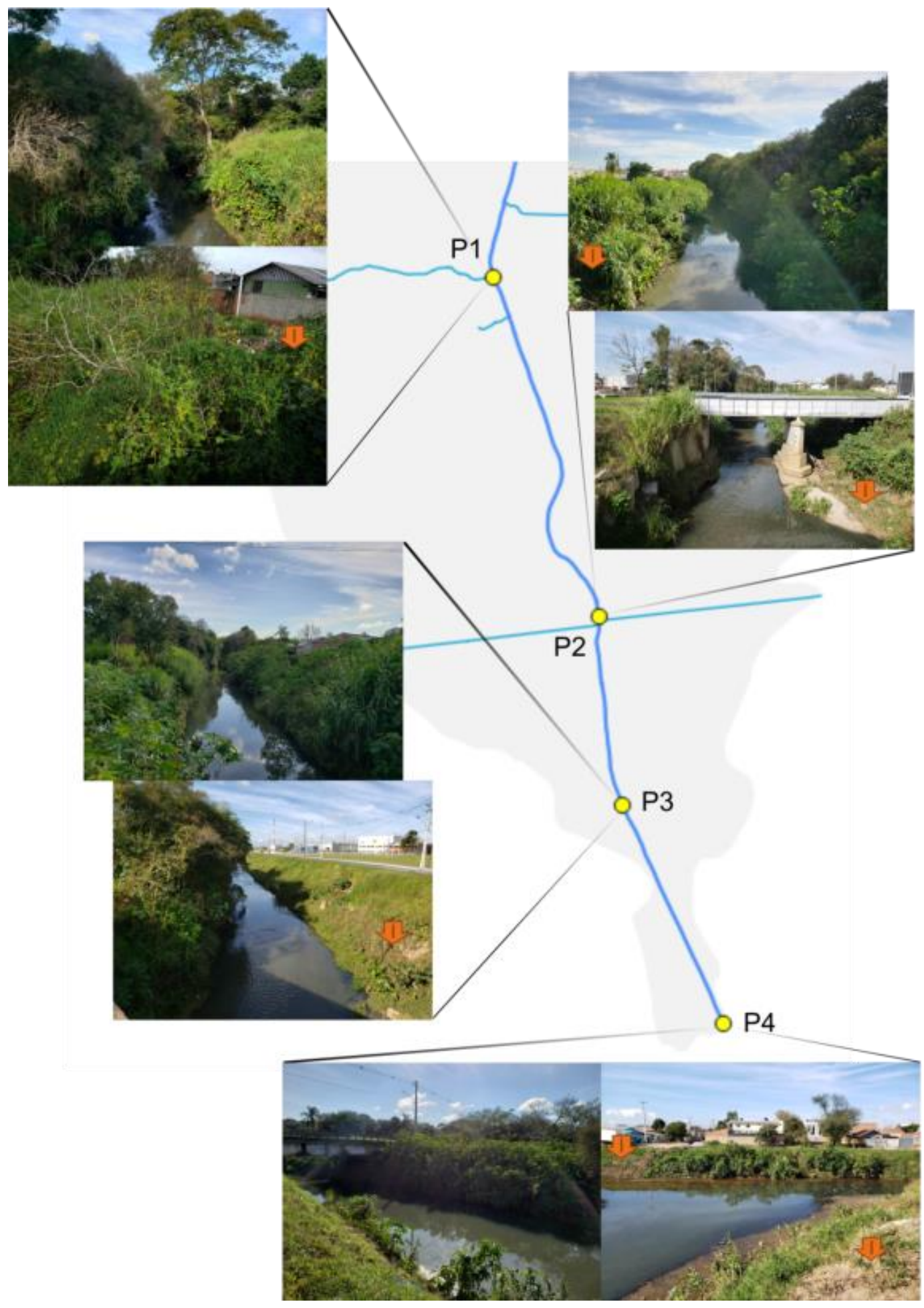

Figura 5 - Ocupação e estabilidade das margens e presença e estado de conservação da mata ciliar nos pontos de observação.

Legenda: = instabilidade das margens.

Fonte: Elaborado pelos autores 


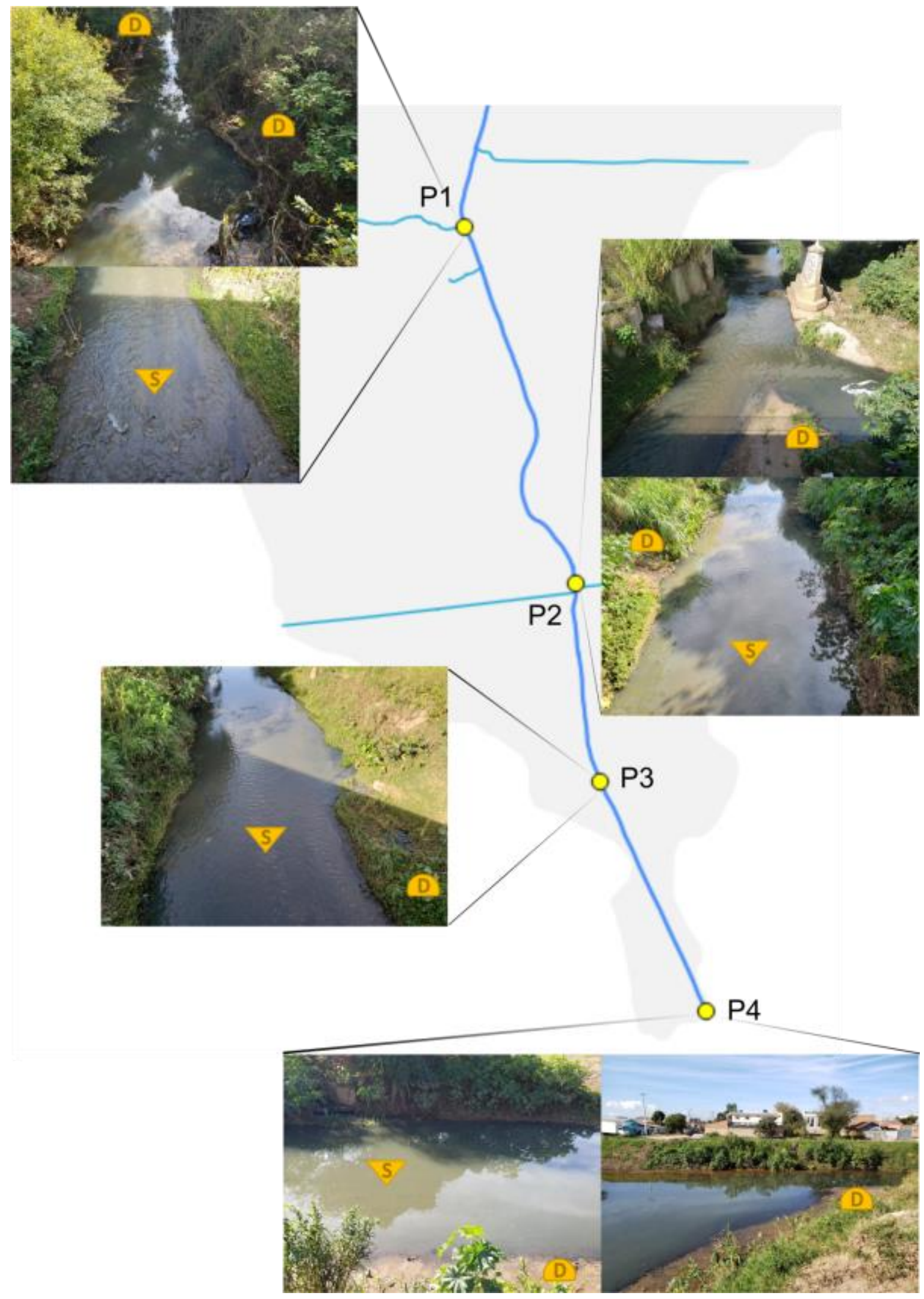

Figura 6 - Deposição de sedimentos e soterramento nos pontos de observação.

Legenda: $D$ = deposição de sedimentos; $\$$ = soterramento.

Fonte: Elaborado pelos autores 


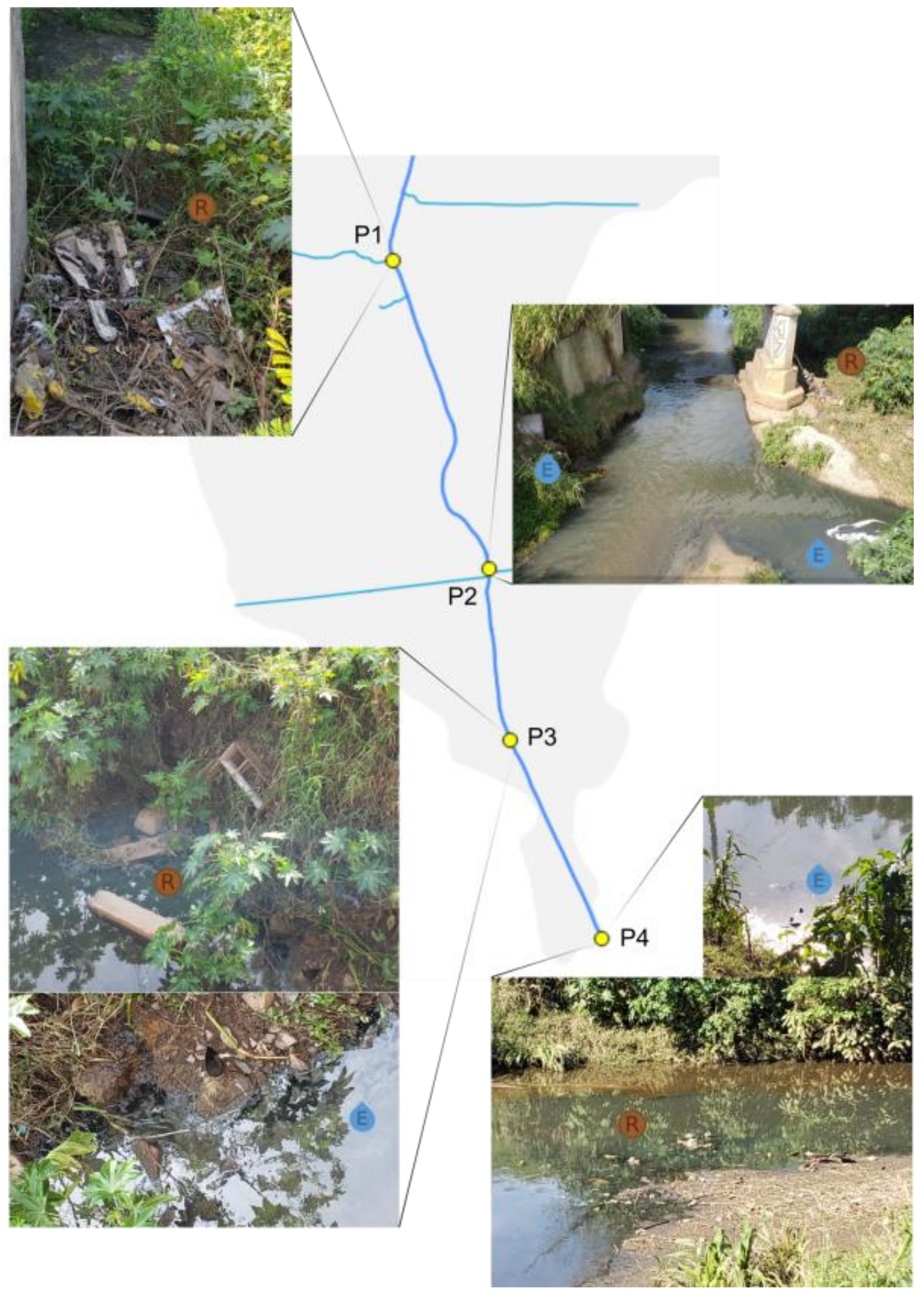

Figura 7 - Resíduos sólidos e efluentes líquidos (esgoto doméstico e efluente industrial) nos pontos de observação.

Legenda: $B$ = resíduos sólidos; ${ }^{*}$ = efluentes líquidos.

Fonte: Elaborado pelos autores 
As alterações antrópicas no canal fluvial também estão presentes em todos os pontos, inclusive por estarem localizados sobre pontes, mas é no ponto 2 que estas alterações são mais acentuadas, tanto pelo porte da construção quanto pela existência de outra ponte próxima.

Sobre o critério animais, foram observadas algumas aves no rio, embora seja importante destacar que no ponto 4 elas estavam em meio aos resíduos sólidos. Os animais são importantes indicadores do estado de conservação de um ecossistema, no entanto, nas condições em que foram observados, provavelmente buscando alimentos nos resíduos, sugere um desequilíbrio, o que apresenta uma contradição. Diante disso, sugere-se a revisão deste critério para trabalhos futuros.

Como ferramenta de monitoramento ambiental, o PARU tem a vantagem de ser acessível economicamente e cognitivamente, pois não necessita de equipamentos sofisticados e onerosos e nem conhecimento técnico específico para seu entendimento e aplicação, podendo ser utilizado como uma ferramenta viável de monitoramento dos ambientes aquáticos, assim como para a educação formal e informal da população.

A condição geral do rio é expressa pelo somatório das notas nos respectivos pontos e isso pode ser uma desvantagem em relação à representatividade da situação por mascarar problemas. Esta mesma constatação é válida para a média das notas das margens direita e esquerda nos critérios que convém. Para amenizar esse problema, sugere-se que as situações críticas extremas sejam descritas para cada ponto analisado.

\section{Conclusões}

Sobre a avaliação das condições do rio, os resultados da aplicação do PARU demonstram que o rio Palmital apresenta impactos negativos relevantes nos pontos analisados; essa situação torna-se ainda mais crítica quando levado em consideração que a avaliação foi realizada em um período de crise hídrica e que o rio Palmital pertence à área de interesse de manancial de abastecimento público da RMC.

Em se tratando da análise do PARU enquanto ferramenta de monitoramento ambiental, podem ser elencadas algumas limitações, por ser um método que leva em consideração a 
análise verticalizada da paisagem, dada pela observação in locu, como a dificuldade de acesso ao rio em áreas urbanas que restringe os pontos de observação e leva a uma descontinuidade da abrangência observada, além da inviabilidade da análise de rios (ou trechos de rios) tamponados. A espacialização dos resultados também apresenta limitações, pois mesmo considerando a influencia da bacia de drenagem nos ambientes fluviais, os dados são pontuais e não podem ser extrapolados para a bacia hidrográfica, pelo menos sem estudos com esse fim.

Em contrapartida, o PARU demonstrou ser uma ferramenta de monitoramento simples e de fácil utilização, podendo, com isso, ser aplicado sem grandes dificuldades por órgãos públicos bem como favorecer a participação popular nas tomadas de decisão, beneficiando a gestão dos recursos hídricos e o planejamento ambiental como um todo.

No caso do planejamento urbano brasileiro, alguns instrumentos norteadores são constituídos com base em consulta e/ou aprovação em audiências públicas, como os Planos de Bacia e Planos Diretores, por exemplo, sendo assim, quanto mais acessível forem as informações, mas efetiva é a participação popular, e o PARU pode contribuir para melhorar essa acessibilidade.

Por fim, o PARU tem o potencial de tornar a participação popular mais ativa no monitoramento dos recursos hídricos, seja por meio de campanhas de monitoramento ou de educação ambiental, conduzidas por Organizações da Sociedade Civil.

\section{Referências bibliográficas}

ALLAN, J. D. Landscapes and rivers capes: The influence of land use on stream ecosystems. Annual Review of Ecology Evolution and Systematics, 2004, vol. 35, p. 257-284.

ANDREOLI, C. et al. Os Mananciais de Abastecimento do Sistema Integrado da Região Metropolitana de Curitiba (RMC). Revista Técnica da Sanepar, Curitiba,1999, vol. 12, №. 12. Disponível em: <http://www.sanepar.com.br/sanepar/sanare/V12/Mananciais/mananciais.html>. Acessoem: 16 jul. 2019.

BARBOUR, M. T.; GERRITSEN, J.; SYDER, B. D.; STRIBLING, J. B. Rapid Bioassessment Protocols for Use in Streams and Wadeable Rivers: Periphyton, Benthic Macroinvertebrates and Fish. 2a ed. Washington, D.C: Environmental Protection Agency, Office of Water, 1999. Relatório Técnico.

BERSOT, MENEZES, ANDRADE. Aplicação do Protocolo de Avaliação Rápida de Rios (PAR) na bacia hidrográfica do rio Imbé - RJ. Ambiência, Maio/Agosto 2015, vol.11, no 2, p. 277-294. DOI:10.5935/ambiencia.2015.02.01.

CALLISTO, M.; FERREIRA, W.; MORENO, P.; GOULART, M. D. C.; PETRUCIO, M. Aplicação de um protocolo de avaliação rápida da diversidade de habitats em atividades de ensino e pesquisa. Acta LimnologicaBrasiliensia, 
2002, vol. 14, no 1, p. 91-98. Disponível em: <http://ablimno.org.br/acta/pdf/acta_limnologica_contents 1401E_files/Artigo 10_14(1).pdf>. Acesso em: 27 fev. 2019.

CALLISTO, M.; MORENO, P. Bioindicadores como ferramenta para o manejo, gestão e conservação ambiental. In: SIMPÓSIO SUL DE GESTÃO E CONSERVAÇÃO AMBIENTAL, 2., 2006, Erechim. Disponível em: <http://labs.icb.ufmg.br/benthos/index_arquivos/pdfs_pagina/Callisto\&Moreno-2006.pdf>. Acesso em: 11 mar. 2019.

CAMPOS, J. C.Protocolo de avaliação rápida de rios urbanos como subsídio ao planejamento da paisagem: estudo de caso da bacia hidrográfica do rio Palmital na região metropolitana de Curitiba (PR). $108 \mathrm{f}$. Dissertação (Mestrado em Geografia) - Programa de Pós-graduação em Geografia, Setor de Ciências da Terra, Universidade Federal do Paraná, $2020 . \quad$ Disponível em:https://www.prppg.ufpr.br/siga/visitante/trabalhoConclusaoWS?idpessoal=76792\&idprograma=40001016 035P1\&anobase=2020\&idtc=1411. Acesso em: 27 jul. 2020.

CAMPOS; J. C.; NUCCI, J. C. Proposta de um protocolo de avaliação rápida para rios urbanos. Revista Geografar,2019,vol. 14, no 2, p. 267-286. <https://revistas.ufpr.br/geografar/article/view/59176/39924>. Acesso em: 08 jan. 2020.

DILLENBURG, A. K. A importância do monitoramento ambiental na avaliação da qualidade de um rio - estudo de caso - Mercedes, PR. Revista Urutágua, 2007, № 12 . Disponível em: <http://www.urutagua.uem.br/012/12dillenburg.pdf. Acesso em: 13 mar. 2019.

EPA (Environmental Protection Agency). Biological criteria for the protection of aquatic life. Division of Water Quality Monitoring and Assessment, Columbus, v.I-III, 1987.

FRANÇA, J. ; SALES, S.; CRUZ, V; RESENDE, F.; SANTOS, R. C.; SOUZA, R.; FREITAS, A.; RIBEIRO, A.; CALLISTO, M. Avaliação ecológica rápida da qualidade das águas (parâmetros físicos e químicos) dos riachos. In: Encontro de Recursos Hídricos em Sergipe, 3., 2010, Aracaju. Disponível em: <http://labs.icb.ufmg.br/benthos/index_arquivos/pdfs_pagina/2010/Francaetal2010-ERHS.pdf>. Acessoem: 13 mar. 2019.

HANNAFORD, M. J.; BARBOUR, M. T.; RESH, V. H. Training reduces observer variability in visual-based assessments of stream habitat. Journal of The North American Benthological Society, 1997, vol. 16, no 4, p. 853-860. Disponível em: <https://www.jstor.org/stable/1468176>. Acesso em: 13 mar. 2019. https://doi.org/10.2307/1468176.

KARR, J. R. Defining and measuring river health. FreshwaterBiology, 1999, vol. 41, p. 221-234. Disponível em: <https://onlinelibrary.wiley.com/doi/abs/10.1046/j.1365-2427.1999.00427.x>. Acesso em: 27 fev. 2019. https://doi.org/10.1046/j.1365-2427.1999.00427.x.

KRUPEK, R. A. Análise Comparativa entre duas bacias hidrográficas utilizando um protocolo de avaliação rápida da diversidade de habitats. Ambiência, 2010, vol. 6, no 1, p. 147-158. Disponível em: <https://revistas.unicentro.br/index.php/ambiencia/article/view/981/989>. Acesso em: 27 fev. 2019.

MINATTI-FERREIRA, D. D.; BEAUMORD, A. C. Avaliação rápida de integridade ambiental das subbacias do rio Itajaí-Mirim no Município de Brusque, SC. Revista Saúde e Ambiente, 2004, vol. 5, no 2, p. 21-27.

MINATTI-FERREIRA, D. D.; BEAUMORD, A. C. Adequação de um protocolo de avaliação rápida de integridade ambiental para ecossistemas de rios e riachos: aspectos físicos. Revista Saúde e Ambiente, 2006, vol. 7, no 1, p. 39-47.

MORIN, E. Introdução ao pensamento complexo. Porto Alegre: Sulina, 2011. 120 p.

PARANÁ (Estado). Decreto no 4435, de 29 de junho de 2016. Declara as Áreas de Interesse de Mananciais de Abastecimento Público da Região Metropolitana de Curitiba e dá outras providências. Diário Oficial do Estado do Paraná. Curitiba, PR, DOEPR no 9730 de 30 de junho de 2016. Disponível em: $<$ https://www.legislacao.pr.gov.br/legislacao/listarAtosAno.do?action=exibir\&codAto=158763\&codltemAto=9 82298>. Acesso em: 16 jul. 2019.

PARANÁ (Estado). Estiagem é ainda mais severa e exige ações emergenciais.Agência de Notícias do Paraná. 2020.Disponível em: <http://www.aen.pr.gov.br/modules/noticias/article.php?storyid=107947>. Acesso em: 03 ago. 2020. 
PIMENTA, M. S; PEÑA, A. P.; GOMES, P. S. Aplicação de métodos físicos, químicos e biológicos na avaliação da qualidade das águas em áreas de aproveitamento hidroelétrico da bacia do rio São Tomás, município de Rio Verde - Goiás. Sociedade \& Natureza, 2009, vol. 21, no 3, p. 393-412. Disponível em: <http://www.scielo.br/pdf/sn/v21n3/a13v21n3.pdf>. $\quad$ Acessoem: $13 \quad$ mar. 2019. http://dx.doi.org/10.1590/S1982-45132009000300013.

RADTKE, L. Protocolos de avaliação rápida: uma ferramenta de avaliação participativa de cursos d'água urbanos. 88 f. Dissertação (Mestrado em Engenharia Civil) - Programa de Pós-graduação em Engenharia Civil, Centro de Ciências Naturais e Exatas, Universidade Federal de Santa Maria, Santa Maria, 2015. Disponível em: https://repositorio.ufsm.br/bitstream/handle/1/7883/RADTKE\%2C\%20LIDIANE.pdf?sequence=1\&isAllowed=y. Acesso em: 20 mai. 2019.

RIGO, D. Gestão das informações ambientais - parte 2. UFES, Vitória, 2005. Apostila. Curso de Especialização em Gestão Ambiental.

RODRIGUES, A. S. de L. Adequação de um protocolo de avaliação rápida para o monitoramento e avaliação ambiental de cursos d'água inseridos em campos rupestres. 118 f. Dissertação (Mestrado em Ciências Naturais) - Programa de Pós-graduação em Evolução Crustal e Recursos Naturais, Departamento de Geologia, Escola de Minas, Universidade Federal de Ouro Preto, Ouro Preto, 2008. Disponível em: http://www.repositorio.ufop.br/bitstream/123456789/2140/1/DISSERTAÇÃO_AdequaçãoProtocoloAvaliação. pdf. Acesso em: 18 mai. 2019.

RODRIGUES, A. S. de L. Uma visão holística sobre os ecossistemas fluviais. Revista da Biologia, 2009, vol. 2, p. 8-11. Disponível em: <http://www.revistas.usp.br/revbiologia/article/view/108562>. Acesso em: 28 jun. 2019.

RODRIGUES, A. S. de L.; CASTRO, P. T. A. Adaptation of a rapid assessment protocol for rivers on rocky meadows. Acta LimnologicaBrasiliensia, 2008, vol. 20, no 4, p. 291-303. Disponível em: <http://ablimno.org.br/acta/pdf/03_200409.pdf>. Acesso em: 17 mar. 2019.

SARAIVA, M. G. A. N.O rio como paisagem: gestão de corredores fluviais no quadro do ordenamento do território. Lisboa: Fundação Calouste Gulbenkian, 1999. 512p.

SECRETARIA DE ESTADO DO MEIO AMBIENTE E RECURSOS HÍDRICOS (SEMA-PR). Bacias hidrográficas do Paraná: série histórica. Curitiba: SEMA-PR, 2010. Relatório Técnico.

SUPERINTENDÊNCIA DE DESENVOLVIMENTO DOS RECURSOS HÍDRICOS E SANEAMENTO AMBIENTAL (SUDERHSA). Plano Diretor de Drenagem para Bacia do Iguaçu na Região Metropolitana de Curitiba. Relatório final, vol. 4, tomo 4.10: Modelagem das linhas de inundação da Bacia do Rio Palmital. Curitiba: SUDERHSA, 2002. Relatório Técnico.

SUDERHSA. Plano de Bacia do Alto Iguaçu e Afluentes do Alto Ribeira. Relatório de Diagnóstico. Curitiba, 2007. Disponível em: http://www.recursoshidricos.pr.gov.br/modules/conteudo/conteudo.php?conteudo=47. Acesso em: 27 nov. 2018.

TUCCI, C. E. M. Água no meio urbano. In: REBOUÇAS, A. C.; BRAGA, B.; TUNDISI, J. G. Águas Doces no Brasil: capital ecológico, uso e conservação. São Paulo: Escritura Editora, 1999. 